\title{
BMJ Open Socioenvironmental criteria and postoperative complications in ambulatory surgery in a French university hospital: a prospective cross- sectional observational study
}

Sorina-Dana Mihailescu (D) , ${ }^{1}$ Isabelle Maréchal, ${ }^{1}$ Denis Thillard, ${ }^{1}$ André Gillibert, ${ }^{2}$ Vincent Compère ${ }^{3}$

To cite: Mihailescu S-D, Maréchal I, Thillard D, et al. Socioenvironmental criteria and postoperative complications in ambulatory surgery in a French university hospital: a prospective cross-sectional observational study. BMJ Open 2020;10:e36795. doi:10.1136/ bmjopen-2020-036795

\section{- Prepublication history for} this paper is available online. To view these files, please visit the journal online (http://dx.doi. org/10.1136/bmjopen-2020036795).

Preliminary data for this study were presented at the SFAR (Anesthesia and Reanimation French Society) meeting in Paris, on the 27th of September, 2018.

Received 03 January 2020 Revised 06 November 2020 Accepted 10 November 2020

Check for updates

(C) Author(s) (or their employer(s)) 2020. Re-use permitted under CC BY-NC. No commercial re-use. See rights and permissions. Published by BMJ.

For numbered affiliations see end of article.

Correspondence to

Professor Vincent Compère; vincent.compere@chu-rouen.fr

\section{ABSTRACT}

Background Ambulatory surgery lowers hospitalisation costs, shortens the time to return to work but requires caution regarding socioenvironmental risk factors for complications and rehospitalisation.

Methods This was a single-centre prospective crosssectional observational study conducted in a university hospital centrein January 2017. The primary objective was to assess the rate of conversion from ambulatory surgery to conventional hospitalisation or emergency department visit within 30 days following discharge from ambulatory unit. Secondary objectives were to describe the socioenvironmental characteristics of outpatients and to identify risk factors for severe postoperative complications.

Results 598 outpatients were included. The most represented surgical specialties were ophthalmology (23.5\%), gynaecology (19\%) and orthopaedics (17.7\%). Patients' mean age was 50.8 years (SD, 19.8) and the male/female sex ratio was 0.68 . There were $22(3.68 \%$, $95 \% \mathrm{Cl} 2.32 \%$ to $5.52 \%$ ) severe complications, including $11(1.84 \%, 95 \% \mathrm{Cl} 0.92 \%$ to $3.27 \%)$ conversions to conventional hospitalisation and $11(1.84 \%)$ conversions to emergency department visit, 3 of which led to readmission. Regarding socioenvironmental characteristics, 116 outpatients (19.7\%) lived alone but were not isolated and $15(2.6 \%)$ lived alone and were socially isolated. Following ambulatory surgery, 9 outpatients $(1.6 \%)$ returned home on foot, $20(3.4 \%)$ by public transportation and $8(1.4 \%)$ drove home; 133 outpatients (13.7\%) were alone the first night following surgery. Severe complication rates were not significantly different according to socioenvironmental subgroups.

Conclusion In our study, the prevalence of severe complications was low, conforming to the literature. The study was underpowered to estimate the effect of socioenvironmental variables.

\section{INTRODUCTION}

Ambulatory surgery currently accounts for the majority of surgical procedures in western countries. Since 2009, the rate of ambulatory surgery is $87 \%$ in Canada (Alberta
Strengths and limitations of this study

- The majority of patients that had ambulatory surgery during a 1-month period were included.

- The standardised collection of information by a single evaluator reinforces the reliability of our data.

- The follow-up at 30 days was performed on patients' medical records in the university hospital centre where the outpatients had received their day surgery.

province), $83.5 \%$ in the USA (with Medicare programme), and ranges from $50 \%$ to $62.5 \%$ in England, Denmark, Netherlands and Sweden. ${ }^{1}$ In France, the objective is to increase the rate of ambulatory surgery from $54 \%$ in 2016 to $66.2 \%$ in 2020 and $70 \%$ in $2022 .^{23}$

Safety in surgery and anaesthesia is traditionally measured by perioperative mortality and morbidity rates. Ambulatory surgery lowers hospitalisation costs, shortens the time to return to work and may decrease the risk of some hospital-related complications such as hospital-acquired infections. However, ambulatory surgery also reduces the time available to monitor severe complications. Readmission in an ambulatory setting may indicate a severe complication that would have been managed earlier if the patient had been hospitalised in a conventional setting. While surgical complication rates are mainly dependent on surgery and patient characteristics, the loss of chance due to ambulatory setting may be better assessed by the rate of readmission or emergency department visits. Another indicator is the rate of conversion from ambulatory surgery to conventional hospitalisation. Conversions are not associated with any loss of chance compared with scheduled 
conventional hospitalisation but may indicate organisational concerns such as the absence of an escort home after discharge. The rate of conversion from ambulatory surgery to conventional hospitalisation varies between $1.34 \%$ and $3.4 \%$, according to studies. ${ }^{4-8}$ The causes can be surgical (pain, bleeding and surgical recovery), anaesthetic (postoperative nausea and vomiting, drowsiness, and aspiration), medical (heart attack, diabetes and thromboembolic event) or socioenvironmental factors (absence of an escort home, insufficient home support and patient request). ${ }^{4}$ In a cohort of 297092 patients, within 30 days after discharge from ambulatory surgery unit, $1.5 \%$ were readmitted to hospital and $9.8 \%$ presented to emergency department but were not readmitted. ${ }^{9}$

Further improvements are needed in the quality of ambulatory surgery. In a series of 285 incidents in a quality management system database during a period of 5 years, $40 \%$ were found to be preoperative (cancellation/ rescheduling, skin preparation, anticoagulation problem, failure to fast), $15 \%$ intraoperative (wrong operative site, technical, anaesthetic incident), and $46 \%$ postoperative. ${ }^{10}$ The low frequency of major complications in ambulatory surgery supports the improvement of procedures regarding the speed of recovery using patient's perceived recovery as outcome. ${ }^{11}$

Appropriate patient selection is the key for a positive outcome and can prevent postoperative complications in ambulatory surgery. ${ }^{12-14}$ Eligibility criteria can vary, according to medical and surgery selection criteria and also psychosocial and environmental criteria. Patients must consent to surgery as well as to day care management. ${ }^{1314}$ In several countries, it is mandatory for patients to be escorted home and monitored at least one night after discharge by a responsible adult. ${ }^{13-15}$ The escort must be able to understand the postoperative care procedures and must accept the responsibility of monitoring the patient. ${ }^{15}$ Long distances between postoperative residence and hospital are not exclusion criteria. Preferably, the distance should not be too long, in order to avoid any delay in emergency rehospitalisation. There is a possibility of agreement between hospitals for the management of some types of complications. Patients should not drive just after their discharge from ambulatory surgery unit. ${ }^{13-15}$ Other factors to be taken into consideration are the accessibility of their home and available equipment, as well as telephone access. ${ }^{13-15}$ The evaluation in the previous articles was done between 1989 and 2010, while our study was conducted in 2017. Since ambulatory surgery has developed substantially in the last years, it was important to evaluate its impact.

Although socioenvironmental variables are taken into account in ambulatory settings, their use is based on expert advice and little is known about the influence of socioenvironmental characteristics on outpatient surgery outcomes. The primary objective of this study was to assess the rate of severe complications in ambulatory surgery, defined as conversion to conventional hospitalisation or emergency department visit within 30 days following discharge from ambulatory unit.

The secondary objectives of this study were to describe the socioenvironmental characteristics of outpatients and to identify risk factors for severe postoperative complications.

\section{METHODS}

\section{Study design}

This single-centre prospective cross-sectional observational study was conducted at Rouen University Hospital, France and the intent was not to intervene. The study is reported following the STrengthening the Reporting of OBservational studies in Epidemiology statement.

\section{Setting}

The study was conducted during a 1-month period in January 2017. Data collection was carried out by a single evaluator, a year-2 public health medical resident. A form was used to manage data entries.

\section{Participants}

All adult patients scheduled for ambulatory surgery at Rouen University Hospital, France, were eligible, regardless of the type of surgery. Non-inclusion criteria were age under 18 years old and patient's refusal.

\section{Variables}

A 4-part questionnaire containing 25 questions was drawn up, according to current recommendations for ambulatory surgery and to the available literature, since there was no validated tool including all the variables that we were interested to collect. In the first part, demographic and socioenvironmental characteristics were collected according to literature review and French recommendations for ambulatory surgery. ${ }^{16}$ The second part contained data related to surgery, including American Society of Anesthesiologists classification of physical status. ${ }^{17}$

The third part included data collected to better describe the profile of outpatients: level of education, lifestyle, with children and their respective age, professional activity and health insurance. The fourth part contained environmental characteristics and variables related to organisation after discharge from the ambulatory unit. These included the means of transportation home, a return home without a patient escort, a return to the home of a patient escort, the presence of a patient escort the first night after surgery, the presence of a telephone at home and the ability to answer it, and a need to be called at 1 week after surgery, the travel time in hours until arrival home, the time the patient plans to be home alone, whether the patient plans to drive within 24 hours following surgery and whether she/he will have to take an important decision within 24 hours following surgery. No validation was needed and no total score was calculated, since it was a multidimensional scale and since we were interested in analysing each item. 
The questionnaire was filled in the postoperative period in the ambulatory surgery unit and before the patient's discharge. One month after discharge, data were collected from the patient's medical records in order to assess the primary endpoint: severe postoperative complications defined as conversion to conventional hospitalisation or to emergency department visit within 30 days after discharge from ambulatory unit, delay chosen according to the literature. ${ }^{9}$

\section{Data sources/measurement}

Data related to surgery were collected from medical records. All other variables were collected from patients' declarations in face-to-face interviews with the primary investigator.

Secondary endpoints were patients' socioenvironmental characteristics.

\section{Bias}

Data collection was carried out by a single evaluator, in order to ensure homogeneous reporting. The quality of data collection was achieved using a form to manage data entries. A representative sample size of ambulatory surgery unit patients was selected in order to provide external validity of the study results.

\section{Study size}

Based on the rate of postoperative complications found in the literature (conversion from ambulatory surgery to conventional hospitalisation or emergency department visit within 30 days following discharge from ambulatory unit), we calculated that 596 patients would be required, with a prevalence estimated at $5 \%$, in order to have a type I error rate corresponding to a coverage probability for confidence intervals of about $5 \%$ and a precision $\varepsilon=0.01750 .^{9}$

\section{Quantitative variables}

Patients with unanticipated hospital admissions were pooled with patients with severe complications as outcome variable because both reflect a severe complication after ambulatory surgery. Detailed results are presented for each of them for further clarity.

\section{Statistical methods}

Patients' characteristics are described by means and SD for continuous variables and by frequencies for categorical variables. Confidence intervals of proportions were calculated by the Clopper-Pearson method. Comparisons of variables according to the occurrence of unanticipated hospital admissions or severe complications were assessed using the skeweness-corrected score 95\% two-sided CIs of risk ratios according to Laud's method. ${ }^{18}$ No multiple testing procedures were applied. The statistical analysis was performed using R software, V.3.5.0. ${ }^{19}$

\section{Patient and public involvement}

No patients involved.

\section{RESULTS \\ Participants}

A total of 598 patients were included, which represented $85.4 \%$ of eligible outpatients (figure 1). Other patients $(n=102)$ were not evaluated because they were less than 18 years old, refused participation, or because they were discharged before the evaluator's assessment.

\section{Descriptive data}

Demographics, anaesthesia and surgery characteristics are presented in table 1.

Socioenvironmental characteristics before ambulatory surgery are shown in table 2.

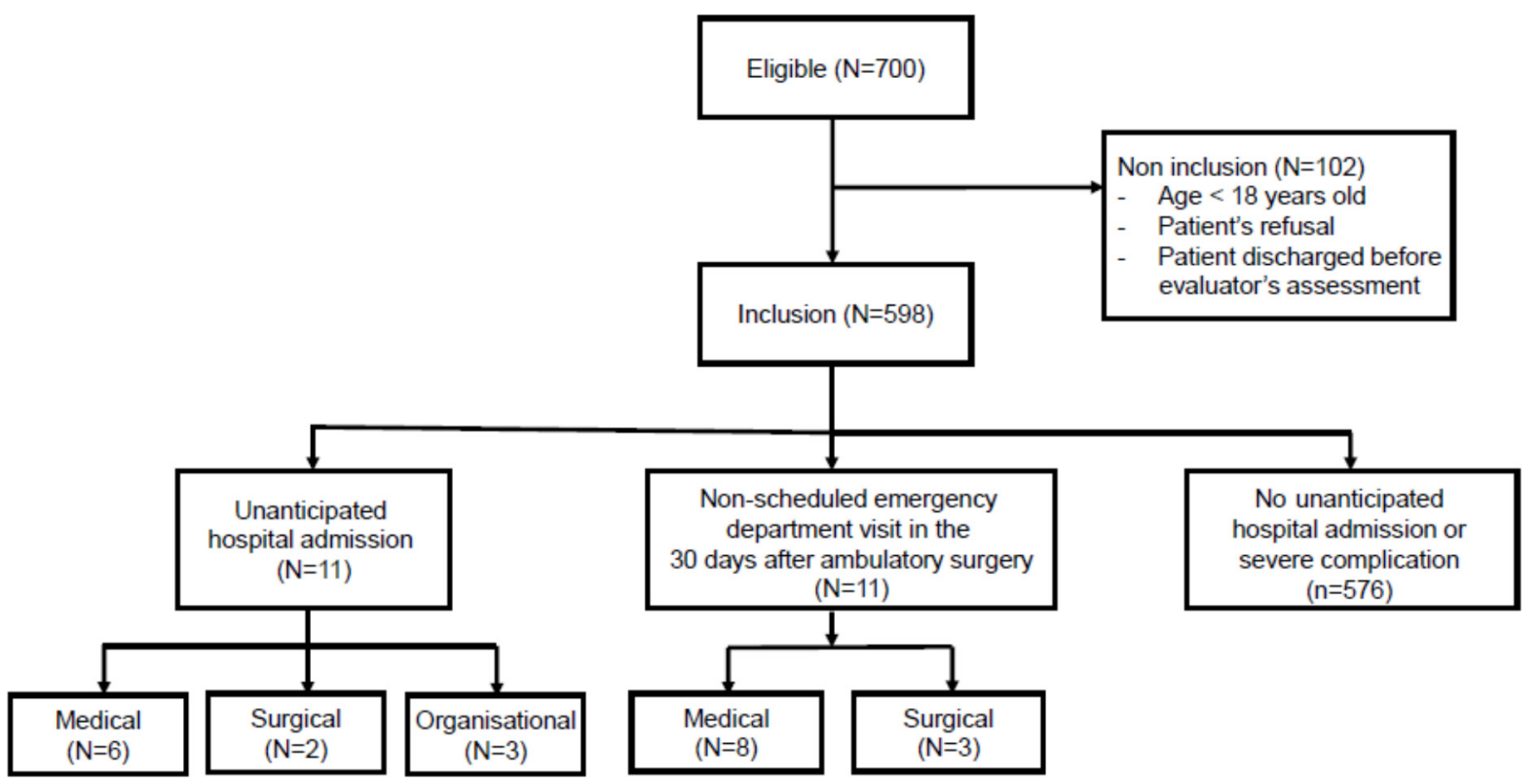

Figure 1 Study design. 
Table 1 Description of population according to medical and surgical characteristics

\begin{tabular}{ll}
\hline Population characteristics & Total $(\mathbf{n}=\mathbf{5 9 8 )}(\mathbf{\%})$ \\
\hline Sex ratio (M/F) & 0.68 \\
Mean age \pm SD (years old) & $50.8 \pm 19.8$ \\
ASA score & \\
1 & $502(84.8)$ \\
2 & $53(9.0)$ \\
3 & $36(6.1)$ \\
4 & $1(0.2)$ \\
\hline
\end{tabular}

Type of anaesthesia

\begin{tabular}{ll} 
General & $281(47.5)$ \\
\hline Locoregional & $99(16.6)$ \\
\hline Leneral and locoregional & $16(2.7)$ \\
\hline Type of surgery & $196(33.2)$ \\
\hline Ophthalmology & $141(23.5)$ \\
\hline Gynaecology & $114(19.0)$ \\
\hline Orthopaedics & $106(17.7)$ \\
\hline Plastic & $50(8.3)$ \\
\hline Ear-nose-throat & $32(5.3)$ \\
\hline Maxillofacial & $29(4.8)$ \\
\hline Hand surgery & $26(4.3)$ \\
\hline Vascular & $20(3.3)$ \\
\hline Arteriography & $17(2.8)$ \\
\hline Pneumology & $16(2.7)$ \\
\hline Odontology & $16(2.7)$ \\
\hline Sismotherapy & $12(2.0)$ \\
\hline General surgery (cholecystectomy, & $8(1.3)$ \\
umbilical hernia, endometriosis, anal & \\
fistula) & \\
MRI & $2(0.3)$ \\
\hline Treatment of iron deficiency & $3(0.5)$ \\
Weekday of intervention & $150(25.1)$ \\
\hline Monday & $115(19.2)$ \\
\hline Tuesday & $120(20.1)$ \\
\hline Wednesday & $115(19.2)$ \\
\hline Friday & $98(16.4)$ \\
\hline Corsday & \\
\hline
\end{tabular}

Continuous variables are expressed as means and SD and categorical variables as frequencies.

ASA, American society of anesthesiologists.

Table 3 shows organisational characteristics after discharge from ambulatory unit.

\section{Outcome data}

The rate of severe complications after day surgery was $3.68 \%$ (95\% CI $2.32 \%$ to $5.52 \%$ ), with $1.84 \%$ (95\% CI $0.92 \%$ to $3.27 \%$ ) of conversions to conventional
Table 2 Description of population according to socioenvironmental characteristics before ambulatory surgery

\begin{tabular}{|c|c|}
\hline Population characteristics & Total $(n=598)(\%)$ \\
\hline Legal protection & $14(2.4)$ \\
\hline Language barrier & $13(2.2)$ \\
\hline \multicolumn{2}{|l|}{ Level of education } \\
\hline Elementary school & $121(20.6)$ \\
\hline Middle school & $139(23.6)$ \\
\hline High school & $74(12.6)$ \\
\hline Baccalaureate/high school diploma & $107(18.2)$ \\
\hline University/college & $147(25.0)$ \\
\hline \multicolumn{2}{|l|}{ Isolation } \\
\hline Alone, not isolated & $116(19.7)$ \\
\hline Alone, isolated & $15(2.6)$ \\
\hline With family, friends or in an institution & $457(77.7)$ \\
\hline With children & $402(68.8)$ \\
\hline \multicolumn{2}{|l|}{ Number of children } \\
\hline $1-2$ & $258(63.7)$ \\
\hline $3-4$ & $117(28.9)$ \\
\hline 5 or more & $30(7.4)$ \\
\hline
\end{tabular}

Age of children (several responses possible if more than one child)

$\begin{array}{ll}\text { 0-5 years old } & 68(14.3) \\ 6-10 \text { years old } & 63(13.3) \\ \text { 11-18 years old } & 66(13.9) \\ >18 \text { years old } & 278(58.5) \\ \text { Professional activity } & \\ \text { Yes } & 244(41.2) \\ \text { Retired } & 191(32.3) \\ \text { No (unemployed, on sick leave, } & 157(26.5) \\ \text { housewife/husband, student, other } & \\ \text { reason) } & \\ \text { Health insurance } & \\ \text { Mandatory } & 10(1.7) \\ \text { Mandatory and supplementary } & 524(91.3) \\ \text { Free universal } & 40(7.0)\end{array}$

Continuous variables are expressed as means and SD and categorical variables as frequencies.

hospitalisation and $1.84 \%$ (95\% CI $0.92 \%$ to $3.27 \%$ ) to emergency department visit within 30 days after discharge from ambulatory unit.

\section{Main results}

The reasons for conversion to conventional hospitalisation are presented in figure 1 . The data of one patient, who refused conversion to conventional hospitalisation despite uncontrolled diabetes mellitus, is not presented in this figure. 


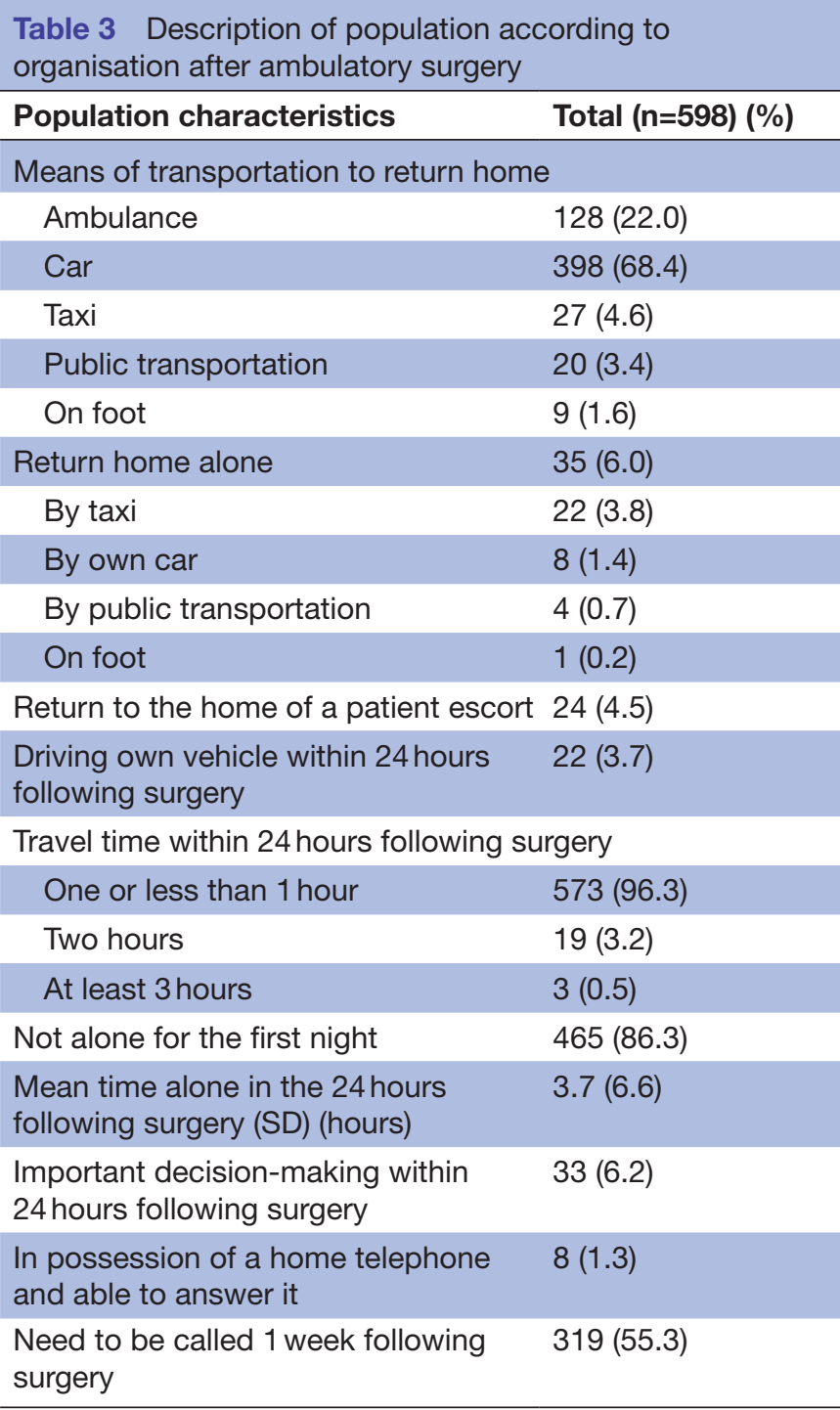

Continuous variables are expressed as means and SD and categorical variables as frequencies.

There were 11 conversions to conventional hospitalisation within the first 30 days after ambulatory surgery: six were for medical reasons, two for surgical reasons and three for organisational reasons. The six medical reasons were: a third degree anaphylaxis after suxamethonium injection with intensive care hospitalisation, pulmonary and urology sepsis, postsurgery hypoxia, nausea and vomiting, pain, and drowsiness and weakening. The two surgical reasons were: a longer laparoscopy time due to the discovery of lymph nodes and a haemorrhage complication during ophthalmology surgery. The three organisational reasons were: a late end-time of surgical interventions that was not compatible with a same-day discharge. Ten patients were discharged the following day and one patient was hospitalised for 48 days (the patient with pulmonary and urology sepsis). The types of surgery leading to conversion were: general surgery $(n=2)$, gynaecology $(n=1)$, maxillofacial $(n=1)$, ophthalmology $(n=1)$, ear-nose-throat $(n=1)$, orthopaedics $(n=2)$, plastic surgery $(\mathrm{n}=1)$, pneumology $(\mathrm{n}=1)$, and vascular surgery $(\mathrm{n}=1)$.

There were 11 conversions to emergency department visit within the first 30 days after ambulatory surgery: $3(27.3 \%)$ at 1 day after surgery, $2(18.2 \%)$ at 2 days, 2 (18.2\%) between 5 and 7 days, $3(27.3 \%)$ between 12 and 14 days, and $1(9.1 \%)$ at 25 days. The reasons for these 11 emergency department visits were: surgical $(n=3)$, sepsis and suture complications; and medical $(n=8)$, pain $(n=4)$, pneumonia $(\mathrm{n}=1)$, cardiac complication $(\mathrm{n}=1)$, arthritis $(n=1)$, and inflammation of venous line $(n=1)$. Among the 11 patients who presented to emergency department, $3(\mathrm{n}=27 \%)$ were hospitalised: 1 for arthritis after material ablation (6 days of hospitalisation with antibiotic therapy), 1 for wound dehiscence (14 days of hospitalisation, wound positive to Staphylococcus aureus methicillin sensitive), and 1 for pneumonia (32 days of hospitalisation, nosocomial infection). The types of surgery were: general surgery $(n=1)$, gynaecology $(n=4)$, orthopaedics $(n=1)$, hand surgery $(n=4)$ and vascular surgery $(n=1)$.

\section{Other analysis}

Table 4 presents the comparison between patients with and patients without complications. There were no significant differences in severe complication rates according to socioenvironmental characteristics. None of the patients with a language barrier had an unanticipated hospital admission or severe complication.

\section{DISCUSSION}

\section{Key results}

In this study, we have assessed socioenvironmental criteria and severe postoperative complications in outpatients. The rate of complications found in our population was $1.84 \%$ which is compatible with the rates found in the largest samples of the literature as $1.34 \%$ in Australia in $1989-1992,{ }^{4} 1.42 \%$ in Canada before 1998 , or $2.67 \%$ in Canada in 2008-2010. ${ }^{6}$

\section{Limitations}

Our study has some limitations, as the single centre design and the follow-up at 30 days that was performed on patients' medical records in the university hospital centrewhere the outpatients had received their day surgery. The number of complications was low so comparisons between outpatients with and without complications were underpowered.

\section{Interpretation}

In our study, the distribution of surgical/medical/socioenvironmental reasons for conversion to conventional hospitalisation was $\mathrm{n}=2(18 \%) / \mathrm{n}=6(55 \%) / \mathrm{n}=3(27 \%)$, which cannot be compared (insufficient statistical precision) to the $\mathrm{n}=80(40 \%) / \mathrm{n}=80(40 \%) / \mathrm{n}=40(20 \%)$ found by Whippey in 200 conversions to conventional hospitalisation in Canada in 2008-2011. ${ }^{6}$ 
Table 4 Relative risk in outpatients with unanticipated hospital admissions or severe complications versus outpatients without unanticipated hospital admissions or severe complications

\section{Outpatients with unanticipated hospital admissions or severe complications $(\mathbf{n}=22)(\%)$}

\section{Outpatients without unanticipated hospital admissions or severe complications ( $n=576)(\%)$}

Risk ratio $(95 \% \mathrm{Cl})$

Type of anaesthesia

General or general with locoregional

Locoregional alone or local

$14(4.7)$

$283(95.3)$

$287(97.3)$

1

0.58 (0.23 to 1.33$)$

Level of education

High school

$11(3.3)$

$323(96.7)$

1

University/college

8 (3.1)

$246(96.9)$

0.96 (0.38 to 2.34$)$

Lifestyle

Alone (isolated or not) 2 (1.5)

$129(98.5)$

437 (95.6)

1

2.67 (0.81 to 16.83$)$

Number of children

$\begin{array}{ll}1-2 & 8(3.1) \\ \geq 3 & 3(2.0)\end{array}$

$250(96.9)$

1

Age of children

0-10 years old

11 years or older

$4(3.8)$

$6(2.1)$

$144(98.0)$

0.68 (0.15 to 2.30$)$

Professional activity

Yes $6(2.5)$

No 13 (3.8)

$3(3.8)$

$238(97.5)$

$101(96.2)$

279 (97.9)

1

0.55 (0.16 to 2.10$)$

Return home following ambulatory surgery

$\begin{array}{ll}\text { Ambulance, car or taxi } & 17(3.1) \\ \text { On foot or public transportation } & 2(6.9)\end{array}$

Return home

\begin{tabular}{|c|c|c|c|}
\hline Escorted & $21(3.7)$ & $542(96.3)$ & 1 \\
\hline Not escorted & $1(2.9)$ & $34(97.1)$ & $0.88(0.04$ to 3.78$)$ \\
\hline \multicolumn{4}{|l|}{ First night after surgery } \\
\hline Alone & $21(4.0)$ & $503(96.0)$ & 1 \\
\hline Not alone & $1(1.4)$ & $73(98.6)$ & $0.39(0.02$ to 1.71$)$ \\
\hline \multicolumn{4}{|l|}{ Driving in relation to surgery } \\
\hline Within 24 hours & $1(4.5)$ & $21(95.5)$ & 1 \\
\hline After 24 hours or no driving & $21(3.6)$ & $555(96.4)$ & $0.70(0.17$ to 14.28$)$ \\
\hline \multicolumn{4}{|c|}{ Travel time within 24 hours following surgery } \\
\hline$\leq 1$ hour & $21(3.6)$ & $555(96.4)$ & 1 \\
\hline$>1$ hour & $1(4.5)$ & $21(95.5)$ & $1.42(0.07$ to 5.95$)$ \\
\hline \multicolumn{4}{|c|}{ In possession of a home telephone and able to answer it } \\
\hline Yes & $21(3.6)$ & $555(96.4)$ & 1 \\
\hline No & $1(12.5)$ & $7(87.5)$ & $3.82(0.20$ to 14.11$)$ \\
\hline
\end{tabular}

Continuous variables are expressed as means and SD and categorical variables as frequencies.

In our study, we found a rate of $1.84 \%$ of emergency department visits within 30 days after ambulatory surgery, slightly less than the $3.7 \%$ reported in a study conducted in Finland in 2007 and a readmission rate of $0.5 \%$ of outpatients, compatible with the $0.7 \%$ observed in the same study. ${ }^{20}$ McIsaac found much higher rates of 30-day emergency department visits $(9.8 \%)$ in 2002-2012 in Ontario, Canada. ${ }^{9}$ The differences may be explained by different surgery types, as authors found risks fourfold higher in general surgery than in plastic surgery, different 
distributions of age and/or comorbidities, and different rates of access to emergency department for the same symptom between countries.

The mean age ( 50.8 years old) in our study was higher than in the general population in France (41.2 years old in 2017), ${ }^{21}$ while male/female sex ratio was 0.68 compared with 0.94 in the general population in France in 2018, according to age structure. ${ }^{22}$ This may be explained by the high number of gynaecology surgeries done in ambulatory surgery in our centre. We found a similar level of education in our sample and in the general population in France in 2014: 20.6\% of outpatients had no diploma or elementary school level vs $25.2 \%$ in the general population, and $25 \%$ had done university/college studies compared with $27.8 \%$ in the general population in France. ${ }^{23}$ The unemployment rate was similar in our sample $(8.5 \%)$ and in the general population in 2017 $(9.4 \%) .^{24}$

We did not find a significant effect of socioenvironmental characteristics on ambulatory surgery patient outcomes but the study was not powered to find one. We wanted to present the descriptive statistical analysis of socioenvironmental criteria in relation to postoperative complications because previous studies only partially evaluated these criteria. Moreover, the area in which and the period during which this study was conducted allowed us to complete existing data in the literature. Another French study reported that among patients screened for ambulatory surgery, $10 \%$ of patients were scheduled to be operated in conventional hospitalisation because of socioenvironmental factors that were not compatible with day surgery. ${ }^{5}$ Their data suggest a potential benefit of collecting outpatients' socioenvironmental characteristics in the planning stage of surgery, allowing patients with a fragile state to be treated in a conventional hospital setting. However, we show that some environmental variables are not always taken into account following ambulatory surgery, as a return home without a patient escort.

In our study, $2.4 \%$ of patients were under legal protection and 2.2\% had a language barrier. National French guidelines for treating patients in an ambulatory surgery setting consider a language barrier, and neurological or psychiatric pathologies that could interfere with a good understanding of surgical procedures to be performed. Theoretically, this can be compensated by the presence of a translator or a tutor, but in practice, this can be a problem when the patient is in the operating room. A language barrier has been shown to be associated with a decreased understanding of the surgical procedure and the severity of complications even if the outpatient previously viewed a supplementary slide presentation with images explaining the surgical procedure. ${ }^{25}$ Another study found that inpatients with limited English stayed $6 \%$ longer in hospital than inpatients with proficient English. ${ }^{26}$

Patients should be escorted home after discharge, since emergency admission may be required if a major complication occurs early. We identified 3.4\%, $1.6 \%$ and $1.4 \%$ of outpatients that returned home by public transportation, on foot, or driving their own car, respectively. A French national study found that $32 \%$ of private hospitals and $60 \%$ of public non-university hospitals had no regulations regarding means of transport home after discharge. A patient escort is usually scheduleded for the outpatient's discharge and for the next 24 hours, but unplanned situations arise. In the present study, $6 \%$ of outpatients declared that they returned home without an escort and $13.7 \%$ that they were alone for the first night after surgery. Interestingly, patients had agreed during their preoperative medical appointment to adhere fully to the instructions for ambulatory surgery. These data were collected on the day of surgery and reflect the sum of failures to either schedule a patient escort or an escort who did not present at the time of discharge. Since it was an observational and not an interventional study, patients were discharged even if they declared that they did not have an escort home or that they would be alone on the first night after surgery. Chung $e t a l^{27}$ showed in Toronto (Ontario) that $60 \%$ of failures were due to escorts not presenting at the time of discharge. Nevertheless, Chung et $a l^{27}$ found a much lower rate of patients without an escort $(0.2 \%, \mathrm{n}=60 / 28391)$. There are several risks associated with discharging patients without an escort after ambulatory anaesthesia and surgery, requiring greater awareness in this context. ${ }^{28}$ Regarding the first period after surgery, $82.8 \%$ of patients stated a need for support during this time. ${ }^{29}$

We found that $3.7 \%$ of patients planned to drive a vehicle within the first 24 hours following surgery, which was similar to the $4 \%$ and $4.1 \%$ found by others for postoperative driving. ${ }^{30} 31$

The main strength of our study is the fact that the majority of patients that had ambulatory surgery during a 1-month period were included. Another strength is the reliability of our data with standardised collection of information by a single evaluator.

\section{Generalisability}

In our study, we found a rate of conversion from ambulatory surgery to conventional hospitalisation comparable to that in the literature. Organisational factors were not optimised for all patients, and some patients had no escort at hospital discharge. Larger-size studies need to be conducted in order to assess the impact of socioenvironmental factors on ambulatory surgery outcomes.

Author affiliations

${ }^{1}$ Rouen University Hospital, Unit for the Prevention of Care-Associated Risks, Rouen, France

${ }^{2}$ Department of Biostatistics, Rouen University Hospital, Rouen, France ${ }^{3}$ Department of Anesthesia and Intensive Care, Normandie Univ, UNIROUEN, Inserm U 982, Rouen University Hospital, Rouen, France

Acknowledgements The authors are grateful to Nikki Sabourin-Gibbs, Rouen University Hospital, for her help in editing the manuscript.

Contributors All authors contributed substantially to the conception and design of the study, data collection, data analysis and its interpretation as it follows: SDM 
and VC: study conception and design, data collection, data analysis, interpretation of data and writing the first draft of the paper; IM and DT: study conception and design, interpretation of data, revising the paper; AG: study conception and design, methodological advice, interpretation of data, revising the paper. All authors checked the final version of the manuscript.

Funding The authors have not declared a specific grant for this research from any funding agency in the public, commercial or not-for-profit sectors.

Competing interests None declared.

Patient and public involvement Patients and/or the public were not involved in the design, or conduct, or reporting, or dissemination plans of this research.

Patient consent for publication Not required.

Ethics approval Ethical approval for this study (No E2016-73) was provided by the Ethics Committee for Non-Interventional Research of Rouen University Hospital, Rouen, France on 24 November 2016. The committee waived the requirements for written informed consent.

Provenance and peer review Not commissioned; externally peer reviewed.

Data availability statement Data are available upon reasonable request. The requests are to be addressed to the corresponding author, Vincent Compère, email: Vincent.Compere@chu-rouen.fr.

Open access This is an open access article distributed in accordance with the Creative Commons Attribution Non Commercial (CC BY-NC 4.0) license, which permits others to distribute, remix, adapt, build upon this work non-commercially, and license their derivative works on different terms, provided the original work is properly cited, appropriate credit is given, any changes made indicated, and the use is non-commercial. See: http://creativecommons.org/licenses/by-nc/4.0/.

ORCID iD

Sorina-Dana Mihailescu http://orcid.org/0000-0001-8545-5087

\section{REFERENCES}

1 International Association for Ambulatory. Surgery, day surgery, development and practice, 2018. Available: http://www.iaas-med. com/files/historical/DaySurgery.pdf

2 Elsevier Masson Blog. Le point sur La Chirurgie ambulatoire en France, 2018. Available: http://www.blog-elsevier-masson.fr/2018/ 01/point-chirurgie-ambulatoire-france/

3 Association Française de Chirurgie Ambulatoire. Taux de chirurgie ambulatoire de 2017 : un ralentissement de sa croissance qui interroge sur l'objectif de $70 \%$ en 2022, 2019. Available: http:// affairesjuridiques.aphp.fr/textes/taux-de-chirurgie-ambulatoire-de2017-association-francaise-de-chirurgie-ambulatoire/telecharger/ 626606

4 Osborne GA, Rudkin GE. Outcome after day-care surgery in a major teaching hospital. Anaesth Intensive Care 1993;21:822-7.

5 Vigier S, Tassin C, Romero G, et al. Day-Care unit for rigid panendoscopy of the upper aerodigestive tract: a study of 436 procedures. Eur Ann Otorhinolaryngol Head Neck Dis 2017;134:393-7.

6 Whippey A, Kostandoff G, Paul J, et al. Predictors of unanticipated admission following ambulatory surgery: a retrospective case-contro study. Can J Anaesth 2013;60:675-83.

7 Lau H, Brooks DC. Predictive factors for unanticipated admissions after ambulatory laparoscopic cholecystectomy. Arch Surg 2001:136:1150-3.

8 Fortier J, Chung F, Su J. Unanticipated admission after ambulatory surgery--a prospective study. Can J Anaesth 1998;45:612-9.

9 Mclsaac DI, Bryson GL, van Walraven C. Impact of ambulatory surgery day of the week on postoperative outcomes: a populationbased cohort study. Can J Anaesth 2015;62:857-65.
10 Slim K, Theissen A, Raucoules-Aimé M, et al. Risk management in ambulatory and short-stay gastrointestinal surgery. J Visc Surg 2016;153:55-60.

11 Stessel B, Fiddelers AA, Joosten EA, et al. Prevalence and predictors of quality of recovery at home after day surgery. Medicine 2015;94:e1553.

12 Australian Day Surgery Council. Melbourne: ADSC, 2004. Available: https://docplayer.net/storage/23/1800970/1606315652/rtpqcUoN OQRaMUSvFydA9A/1800970.pdf

13 Association of Anaesthetists of Great Britain and Ireland, British Association of Day Surgery. Day case and short stay surgery: 2. Anaesthesia 2011;66:417-34.

14 Société française d'anesthésie et de reanimation Recommandations formalisées d'experts. Prise en charge anesthesique des patients en hospitalisation ambulatoire. Annales Françaises d'Anesthésie et de Réanimation 2010;29:67-72.

15 International association for ambulatory surgery. Policy brief day surgery: making it happen. London: IAAS, 2007. http://www.euro. who.int/_data/assets/pdf_file/0011/108965/E90295.pdf

16 Hauté Autorité de Santé. Ensemble pour Le développement de la Chirurgie ambulatoire, 2018. Available: https://www.has-sante.fr/ portail/upload/docs/application/pdf/2013-05/guide_securite_du_ patient en chirurgie ambulatoire.pdf

17 Keats AS. The ASA classification of physical status--a recapitulation. Anesthesiology 1978;49:233-5.

18 Laud PJ. Equal-tailed confidence intervals for comparison of rates. Pharm Stat 2017;16:334-48.

19 R Core Team. R: a language and environment for statistical computing. Vienna, Austria: R Foundation for Statistical Computing, 2018. URL https://www.R-project.org/

20 Mattila K, Hynynen M, Intensium Consortium Study Group. Day surgery in Finland: a prospective cohort study of 14 day-surgery units. Acta Anaesthesiol Scand 2009;53:455-63.

21 Institut national de la statistique et des études économiques. Âge moyen et âge médian de la population en 2018. Données annuelles de 1991 2018., 2018. Available: https://www.insee.fr/fr/statistiques/ 2381476

22 Institut national de la statistique et des études économiques. Population totale PAR sexe et âge Au 1er janvier 219, France métropolitaine, 2019. Available: https://www.insee.fr/fr/statistiques/ fichier/1892088/pop-totale-france-metro.xls

23 Observatoire des inégalités. 16\% de la population a un diplôme supérieur bac+2, 2019. Available: https://www.inegalites.fr/16-de-lapopulation-a-un-diplome-superieur-a-bac-2

24 Institut national de la statistique et des études économiques. Chômage Au senS Du bit et indicateurs sur Le marché Du travail. Available: https://www.insee.fr/fr/statistiques/2966612 [accessed 15 Jannuary 2019]

25 Clark S, Mangram A, Ernest D, et al. The informed consent: a study of the efficacy of informed consents and the associated role of language barriers. J Surg Educ 2011;68:143-7.

26 John-Baptiste A, Naglie G, Tomlinson G, et al. The effect of English language proficiency on length of stay and in-hospital mortality. $J$ Gen Intern Med 2004;19:221-8.

27 Chung F, Imasogie N, Ho J, et al. Frequency and implications of ambulatory surgery without a patient escort. Can $J$ Anaesth 2005;52:1022-6.

28 Ip HYV, Chung F. Escort accompanying discharge after ambulatory surgery: a necessity or a luxury? Curr Opin Anaesthesiol 2009;22:748-54.

29 Brattwall M, Warrén Stomberg M, Rawal N, et al. Patients' assessment of 4-week recovery after ambulatory surgery. Acta Anaesthesiol Scand 2011;55:92-8.

30 Correa R, Menezes RB, Wong J, et al. Compliance with postoperative instructions: a telephone survey of 750 day surgery patients. Anaesthesia 2001;56:481-4.

31 Cheng CJC, Smith I, Watson BJ. A multi centre telephone survey of compliance with postoperative instructions. Anaesthesia 2002;57:778-817. 